\title{
Development of Rigid Polyurethane Foam (RPUF) for Imitation Wood Blown by Distilled Water and Cyclopentane (CP)
}

\author{
Ratchanon Boonachathong ${ }^{1}$, Bordin Kaewnok ${ }^{2}$, Halim Widjaja ${ }^{2}$, and Suksun Amornraksa ${ }^{1}$ \\ ${ }^{1}$ the Department of Mechanical and Process Engineering, The Sirindhorn International Thai-German Graduate School of Engineering, King \\ Mongkut's University of Technology North Bangkok, Bangkok, Thailand \\ ${ }^{2}$ Technical Service and Development Department, Covestro, PUR system house, Samut Prakan, Thailand
}

\begin{abstract}
Rigid polyurethane foam (RPUF) used for imitation wood is typically prepared by using 1-dichloro-1fluoroethane (HCFC-141b) as a blowing agent. However, this chemical is a hydrofluorocarbon which severely causes ozone depletion to the atmosphere. In this study, a more environmental-friendly RPUF was prepared by using distilled water and cyclopentane (CP) as alternative blowing agent. Several properties of the prepared RPUF were investigated and measured such as density $\left(\mathrm{kg} / \mathrm{m}^{3}\right)$, surface hardness (Durometer, type $\mathrm{D}$ ), and glass transition temperature $\left({ }^{\circ} \mathrm{C}\right)$ using differential scanning calorimeter (DSC). It was found that when the amount of blowing agents decreased, the foam density was increased as well as the surface hardness. The developed RPUF with CP co-blown has higher surface hardness and glass transition temperature compare to pure water-blown RPUF at the same density $\left(353 \mathrm{~kg} / \mathrm{m}^{3}\right)$. And the new RPUF produced has a good potential to substitute for a conventional RPUF.
\end{abstract}

\section{Introduction}

Rigid polyurethane foam (RPUF) is a very useful thermoset polymer. It has been used in several applications, for example, automotive parts, appliance and construction materials, insulation, e.g. freezers, imitation woods and decoration products [1]. For imitation wood, there are several product properties that are of important concerns such as strength, thermal stability, and light weight.

RPUF is typically produced by reaction of polyol and Methane diphenyl diisocyanate (MDI). The reaction occurs simultaneously and yields polyurethane foam and carbon dioxide gas as products. The reaction is exothermic. The chemical structures of MDI, polyol and chemical reactions are illustrated in the Figure 1 and Figure 2 [2].

$$
\begin{aligned}
& \mathrm{R}_{1}-\mathrm{N}=\mathrm{C}=\mathrm{O}+\mathrm{HO}-\mathrm{R}_{2} \rightarrow \mathrm{R}_{1}-\mathrm{N}-\mathrm{N}-\mathrm{C}-\mathrm{O}-\mathrm{R}_{2} \\
& \mathrm{R}_{1}-\mathrm{N}=\mathrm{C}=\mathrm{O}+\mathrm{H} 2 \mathrm{O} \longrightarrow \stackrel{\mathrm{R}}{\mathrm{H}} \stackrel{\mathrm{O}}{\mathrm{N}}-\mathrm{N}-\mathrm{C}-\mathrm{OH} \longrightarrow \mathrm{CO}_{2}+\mathrm{R}_{1}-\mathrm{NH}_{2}
\end{aligned}
$$

Figure 1. Primary reactions: polymerization (condensation) and foaming reaction of RPUF produced urethane and amine with carbon dioxide reactions (1) and (2) respectively.

Two main reactions for polyurethane formation are polymerization and foaming reaction. For polymerization, the isocyanate (MDI) reacts with polyol and forms urethane linkage (1). At the same time, MDI reacts with water and forms unstable carbamic acid which decomposed to carbon dioxide $\left(\mathrm{CO}_{2}\right)$ and amine in foaming reaction (2) [3].

Then, products of primary reactions can continue reacting with MDI.

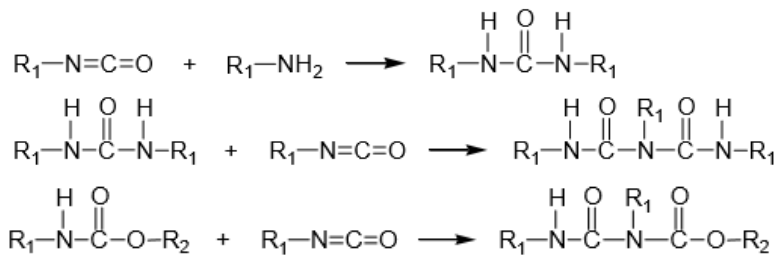

Figure 2. Secondary reactions of produced RPUF prouduced urea, biuret and allophanate; reactions (3), (4) and (5) respectively.

Amine reacts with MDI and produces urea. This urea forms hard segment phases, polyuria (3). Urea reacts with MDI and forms Biuret (4). During the rising of temperature from exothermic reaction, urethane from equation 1 may also react with excess quantity of MDI and produce allophanate (5). This allophanate is considered a crosslinker in RPUF [4].

The obtained rigid polyurethane foam has close cell structure [5]. The cellular structure of rigid foam is formed by means of chemical and physical blowing agent. An example of chemical blowing agents for RPUF is distilled water. It reacts with MDI and generates polyuria, polybiuret and carbon dioxide as described by (2)-(4). The produced gas bubbles create cellular structure of the rigid foam. Another method to produce foam structure is via the evaporation of physical blowing agents. The evaporation is promoted by exothermic heat from the 
reaction. There are also other blowing agents that can be used in RPUF production, depending on required product properties and costs.

Blowing agent is a substance that is able to produce a cellular structure via a foaming process in a variety of materials that undergo hardening or phase transition, such as polymers, plastics, and metals. Blowing agent occupy $95-97 \%$ of the foam volume. It contributes around 50$70 \%$ to the overall foam conductivity [6]. Hence, it has significant influence on insulation property.

Traditionally, auxiliary blowing agent that is widely used in production of polyurethane foam is trichlorofluorocarbon (CFC-11). However, according to the Montral protocol in 1987, chlorofluorocarbons (CFCs) blowing agent was banned in industrial due to contained Halogens which is harmful to the ozone layer, and consequently contributes to global warming and other environmental problems. So, its utilization is gradually decreased. In addition, the Kigali amendment referring to Montreal protocol states that 1-Dichloro-1-fluoroethane (HCF-141b) has to be replaced (phase-out) due to the depletion of ozone layer. The main context of the amendment is to gradually reduce $80-85 \%$ consumption of HFC substances used by 2040. Moreover, the Copenhagen Amendment outlines the phase-out allows HCFC consumption between 1996 and 2040 [7], [8].

The search for alternative blowing agent to replace CFCs in polyurethane foams has been a challenge due to numbers of important factors. Concerned factors are environmental consideration; air pollution, feasibility consideration; toxicity, flammability, compatibility with materials of construction, safety and economic manufacturing process, etc. Several studies showed that the selection of blowing agent is very crucial as it can directly affect physical and thermal properties of RPUF. So, many alternative blowing agents for polyurethane foam have been studied base on available formulation and production technology to overcome those challenges.

There are numbers of studies that are associated with water-blown foam, e.g., foam stability, flow ability, foam strength and etc. Water $\left(\mathrm{H}_{2} \mathrm{O}\right)$ is a non-ozone depleting, non-toxic and affordable blowing agent. Researches on water blown rigid foams and their applications have performed investigation on water level and its effect to rigid foam. The studies found that water is an important part in determining the RPUF density $\left(\mathrm{kg} / \mathrm{m}^{3}\right)$. The density of RPUF can be increased by decreasing the amount of water $[9,10]$.

Cyclopentane $\left(\mathrm{C}_{5} \mathrm{H}_{10}\right)$ is an alicyclic hydrocarbon. It has a boiling point at $49.2{ }^{\circ} \mathrm{C}$. It behaves as physical blowing agent in RPUF. When temperature is rising due to heat of reaction, $\mathrm{CP}$ will evaporate and create foam structure. In a study by Li Xiaobin et al., they evaluated and compared the performance of water and cyclopentane. Their results showed that the reaction times of CP full blown are longer compared to waterborne recipe [11].

The present of rigid structures i.e. aromatic rings of MDI and increasing of crosslink density in RPUF lead to increase of glass transition temperature (Tg). Studies showed that higher glass transition temperature is possible when increasing amount of MDI and water in during product formulation [12-14]. Moreover, when distilled water is used the mobility of polymer chain can be restricted and results in increasing of glass transition temperature [15-17].

In this study, the composition of isocyanate (MDI) used in the preparation of RPUF is the same quantity (same ratio of ROH: RNCO). The performance of RPUF prepared from distilled water and cyclopentane blowing agents are investigated. Cyclopentane will be used as coblowing agent ( $\mathrm{CP}$ co-blown) with distilled water. Key properties for the imitation wood RPUF product are measured. They are density $\left(\mathrm{kg} / \mathrm{m}^{3}\right)$, surface hardness (shore D), and glass transition temperature (Tg). Materials and characterization methods used for the RPUF prepared from distilled water and cyclopentane as blowing agent are described in the following sections.

\section{Experiments}

\section{1 materials}

The chemicals used for preparation of RPUF samples in this study were supplied by Covestro, polyurethane system house, Thailand (former Bayer material science). Methane diphenyl diisocyanate (MDI) used has an average functionality of 2.7 and characterized by $\mathrm{NCO} \%=30.3-31.2$, viscosity at $25 \mathrm{C}$ is $210-230 \mathrm{mPa}$ s.

Polyol-1 is a long chain polymer. It is propylene glycol initiator with average functionality 2, hydroxyl value $113-120 \mathrm{mgKOH} \mathrm{g}^{-1}$. The viscosity at $25^{\circ} \mathrm{C}$ is 150 mPa s.

Polyol-2 is a short chain polymer. It is sucrose initiator with average functionality 3-4, hydroxyl value $350-360 \mathrm{mgKOH}$ g- 1 . The viscosity at $25^{\circ} \mathrm{C}$ is $3000 \mathrm{mPa}$ s.

Catalyst-1 contains $33 \%$ of triethylene Diamine (TEDA) and $67 \%$ of dipropylene glycol. It is used to promote gel reaction.

Catalyst- 2 is methyl imidazolium. It is used to improve adhesion.

Silicone is used as foam stabilizer. It emulsifies the mixing of RPUF and creates fine cell foam size.

Glycerin $\left(\mathrm{C}_{3} \mathrm{H}_{8} \mathrm{O}_{3}\right)$ is a plain polyol compound containing 3 hydroxyl groups. It has a short chain structure which can increase level of crosslink in RPUF. Blowing agent-1, 2 are distilled water (generated in our laboratory) and cyclopentane (CP).

\subsection{Preparation of rigid polyurethane foam samples}

The laboratory works includes formulation, free rise hand foam and mold tests $(20 \mathrm{~cm} \times 10 \mathrm{~cm} \times 2 \mathrm{~cm})$. The RPUF were prepared by hand mixing technique, by mixing polyol with catalysts 1,2 , and additives together. Once well-mixed, blowing agents 1 and 2 were added into the formulated polyol (circa. 20-25 ${ }^{\circ} \mathrm{C}$ ) and mixed for 6 seconds. The stirrer speed was set at 3000 rounds per minute (rpm) for entire experiment.

The reaction times (second) for creaming, gelling and tracking free times were observed via free rise hand foam in plastic cup $(200 \mathrm{ml})$. The amounts of blowing agents, 
distill water and cyclopentane is varied to obtain the desired reaction times and density $\left(\mathrm{kg} / \mathrm{m}^{3}\right)$.

Then, properties of rigid foam sample will be examined via mold test. Mold temperature before pouring the mixed chemicals is controlled at $40-42{ }^{\circ} \mathrm{C}$. During mold test, density of the sample was varied by different input weights of mixed chemicals. The mixed chemicals were poured into the constant mold volume. The mold was closed for 10 minutes before being opened to measure density.

The composition of raw materials with different blowing agents used in this work to prepare RPUF are summarized and shown in Table 1.

Table 1. Chemical compositions of RPUF, prepared at $20^{\circ} \mathrm{C}$.

\begin{tabular}{lcccc}
\hline \multirow{2}{*}{ Composition (pphp) } & \multicolumn{5}{c}{ Recipe } \\
\cline { 2 - 5 } & $\mathbf{1}$ & $\mathbf{2}$ & $\mathbf{3}$ & $\mathbf{4}$ \\
\hline Polyol 1 and 2 & 100 & 100 & 100 & 100 \\
Glycerin & 1.5 & 1.5 & 1.5 & 1.5 \\
Silicone & 1 & 1 & 1 & 1 \\
Catalyst 1 and 2 & 1.2 & 1.2 & 1.2 & 1.2 \\
Distilled water & 0.63 & 0.5 & & \\
Cyclopentane & & 0.5 & 2.46 & 1.23 \\
\hline
\end{tabular}

Isocyanate index 105

pphp: parts per 100 parts of polyol

by weight $(\mathrm{g})$

Mixing ratio; $\mathrm{ROH}: \mathrm{RNCO}=1: 1$

The quantity of blowing agent used in this study is controlled base on mole of produced blowing gas. From reaction (1), considering stoichiometry, one mole of water reacted with MDI will produce one mole of carbon dioxide. Considering the recipe 2 (CP co-blown), 0.5 gram of water produced circa. 0.028 mole of gas (CO2). Likewise, 0.5 gram of $\mathrm{CP}$ produced 0.00713 mole of gas (CP). The total produced gas is 0.03513 mole. Thus, for the recipe 1 (full waterborne), the used quantity of water is circa. 0.6324 gram. So, the same amount of gas (mole) can be produced. In case of recipe 3 (full CP blown), it required circa. $2.46 \mathrm{~g}$ accordingly. Practically, high amount of $\mathrm{CP}$ is not preferred due to flammability concerns. So, in this study, we did not do thermal analysis for recipe 3 and 4 . However, the comparisons of reaction times are still observed and shown in next section.

Prepared 10 RPUF samples of recipe 1 and 2 have density between $218-353 \mathrm{~kg} / \mathrm{m}^{3}$. The density is controlled by weight. The RPUF samples are left for 24 hours to ensure that the cure is stable before measuring surface hardness (shore D). The average value of the surface hardness from upper and lower side of the RPUF is then measured.

Finally, the sample recipe 1 and 2 with density of 353 $\mathrm{kg} / \mathrm{m}^{3}$ were analyzed for thermal property by using DSC.

\subsection{Analytical methods}

Density $\left(\mathrm{kg} / \mathrm{m}^{3}\right)$ was measured according to ASTM D 1622-8 standard. The RPUF sample densities were calculated via mass over volume. The RPUF samples were prepared by mold (size $10 \mathrm{~cm} \mathrm{x} 20 \mathrm{~cm}$ x $1 \mathrm{~cm}$ ). In this study, prepared samples have density between 218 to $353 \mathrm{~kg} / \mathrm{m}^{3}$.

Surface hardness is measured using Durometer tester, Teclock GS-707 (Shore D), DIN ISO 7619-1 standard. The RPUF samples were prepared by mold $(10 \mathrm{~cm}$ x 20 $\mathrm{cm} \times 1 \mathrm{~cm})$. After 12 hours, the surface hardness of the sample is measured.

Differential scanning calorimeter (DSC Q2000 V24.11) was used to measure glass transition temperature $\left(\mathrm{T}_{\mathrm{g}}\right)$ of rigid foam samples. The samples were investigated at nitrogen flow rate of $60 \mathrm{~mL} / \mathrm{min}$, heating rate of $15^{\circ} \mathrm{C}$ per minute to $300^{\circ} \mathrm{C}$.

\section{Results and discussions}

\subsection{Reaction times of RPUF using blowing agents, distilled water and cyclopentane}

From prepared chemicals compositions of study RPUF, the reaction times are shown in Table 2.

Table 2. Reaction times of RPUF using blowing agent, distilled water and cyclopenthane.

\begin{tabular}{lcccc}
\hline Composition (pphp) & $\mathbf{1}$ & $\mathbf{2}$ & $\mathbf{3}$ & $\mathbf{4}$ \\
\hline Cream time (s) & 41 & 37 & 39 & 65 \\
Gel time (s) & 89 & 80 & 96 & 96 \\
Tack free time (s) & 119 & 105 & 165 & 121 \\
Free rise density $\left(\mathrm{kg} / \mathrm{m}^{3}\right)$ & 166 & 136 & 52.7 & 222 \\
\hline
\end{tabular}

Isocyanate index 105

pphp: parts per 100 parts of polyol

by weight $(\mathrm{g})$

Mixing ratio; $\mathrm{ROH}: \mathrm{RNCO}=1: 1$

RPUF prepared by recipe 1 (pure water blown) had a shorter reaction times compared to cyclopentane $(\mathrm{CP})$ full blown in recipe 3 and 4 due to the effect of exothermic heat reaction. The produced heat causes the reaction move forward faster. So, it takes shorter time to complete the reaction. Meanwhile, recipe 3 and 4 required longer times to complete the reaction. The reason is that $\mathrm{CP}$ in those recipes requires longer time to absorb heat in evaporation. Recipe 3 has longer reaction times compared to recipe 4 due to higher amount of CP. The presence of higher amount of $\mathrm{CP}$ results in longer reaction times regarding the absorption heat, to change from liquid to vapor.

It can be seen that RPUF prepared by recipe 2, CP coblown yielded proper reaction times. From the viewpoint of commercial scale of RPUF production, the reaction times of this recipe are suitable for up-scaling.

3.2 Effect of blowing agents on density $\left(\mathrm{kg} / \mathrm{m}^{3}\right)$ and surface hardness (shore $\mathrm{D}$ ) of rigid foams 
In this work, the averages of upper and lower side of the RPUF surface were measured. The relationship of density and surface hardness using distilled water as a chemical blowing agent (recipe 1) is illustrated in Figure 3 below.

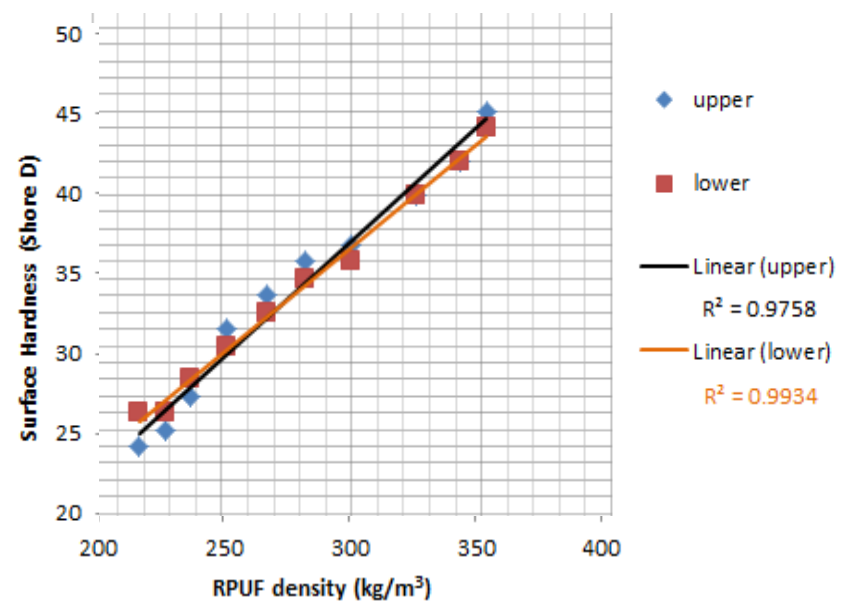

Figure 3. Relationship of density $\left(\mathrm{kg} / \mathrm{m}^{3}\right)$ and surface hardness (shore D) using distilled water as a blowing agent.

Considering the increased density from 218 to 353 $\mathrm{kg} / \mathrm{m} 3$, the surface hardness (shore D) is increased both on the upper and lower side of the sample. The average surface hardness on the upper and lower side at density $353 \mathrm{~kg} / \mathrm{m}^{3}$ are 45 and 44 respectively. Likewise, the relationship of density $\left(\mathrm{kg} / \mathrm{m}^{3}\right)$ and surface hardness (shore D) using water and cyclopentane as a co-blowing agent is illustrated in Figure 4 below.

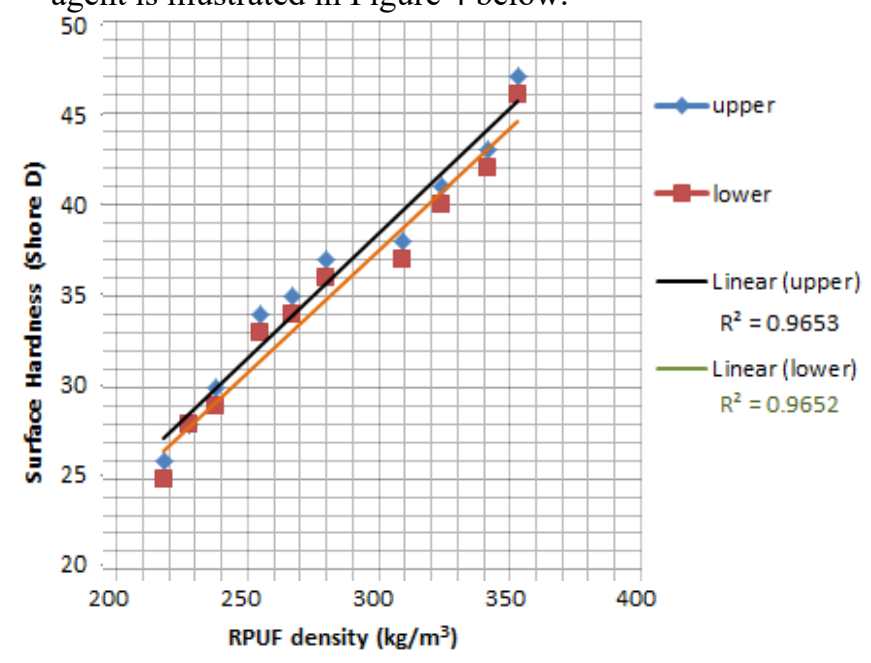

Figure 4. Relationship of density $\left(\mathrm{kg} / \mathrm{m}^{3}\right)$ and surface hardness (shore D) using distilled water and cyclopentane co-blown as blowing agent.

Similar to full water blown, when density is increased from 218 to $353 \mathrm{~kg} / \mathrm{m}^{3}$, the surface hardness (shore D) is increased both on the upper and lower side of the sample. However, the surface hardness of cyclopentane co-blown (recipe 2) is higher compared to pure water blown at the same density. The average surface hardness on RPUF using CP co-blown at the upper and lower side (density $353 \mathrm{~kg} / \mathrm{m}^{3}$ ) is 47 and 46 respectively. The reason that water blown recipe has less surface hardness may be because of biuret formation at the surfaces. This white solid biuret causes brittleness to RPUF surfaces and results in lower surface hardness. The $\mathrm{R} 2$ value indicates that the surface hardness of RPUF is relatively depending on RPUF density for both blowing agents.

\subsection{Effect of blowing agents level on glass transition temperature of rigid foams}

RPUF samples in both cases of blowing at the same density were investigated for glass transition temperature $\left({ }^{\circ} \mathrm{C}\right)$ by DSC analysis. The glass transition temperature of pure water blown (recipe 1) and cyclopentane co-blown (recipe 2) are shown in Table 3.

Table 3. Glass transition temperature of pure water and cyclopentane co-blown.

\begin{tabular}{lcc}
\hline & Recipe 1 & Recipe 2 \\
& Glass transition temperature $\left({ }^{\circ} \mathbf{C}\right)$. \\
\hline at density $353 \mathrm{~kg} / \mathrm{m}^{3}$ & 215.95 & 218.84 \\
\hline
\end{tabular}

From DSC analysis result, glass transition temperature of cyclopentane co-blown is found to be higher $\left(218.84{ }^{\circ} \mathrm{C}\right)$ compared to pure water blown recipe $\left(215.95^{\circ} \mathrm{C}\right)$. According to the network formation theory [18], the increasing of $T_{g}$ illustrates higher crosslink at the surface of RPUF CP co-blown.

\section{Conclusions}

Water and cyclopentane (CP) co-blown can be used to produce environmental friendly rigid polyurethane foam (RPUF). The combination of both blowing agents can produce imitation wood product with desired properties, and yield proper reaction times, density $\left(\mathrm{kg} / \mathrm{m}^{3}\right)$ and surface hardness (shore D).

The cyclopentane co-blown provides alternative reaction times to produce RPUF. The combination of exothermic heat release and heat absorption of water and $\mathrm{CP}$ results in the optimal time of RPUF reaction. The reaction time is longer with a higher content of $\mathrm{CP}$ due to heat absorption of CP.

Surface hardness of RPUF is increased when density is increased. RPUF prepared by CP co-blown recipe has a higher surface hardness (shore D: 47) compared to the full distill water blown (shore D: 45) at the same density $\left(353 \mathrm{~kg} / \mathrm{m}^{3}\right)$ due to condensed chemicals at the surfaces. Meanwhile polyuria (biuret) formed at RPUF surfaces prepared by water blown has less surface hardness.

Glass transition temperature $\left(\mathrm{T}_{\mathrm{g}}\right)$ of the $\mathrm{CP}$ co-blown RPUF is slightly higher. It is increased from $215.95{ }^{\circ} \mathrm{C}$ to $218.84{ }^{\circ} \mathrm{C}$ for water and $\mathrm{CP}$ co-blown recipe respectively. This indicates that at the surface of CP co-blown RPUF has higher crosslink than the pure water-blown recipe. The CP co-blown RPUF creates condense chemicals at the RPUF surface. It results in higher surface hardness and higher glass transition temperature compared to pure the distill water blown RPUF. 
Lastly, the obtained results of the present work show that further studies should focus on decomposition of RPUF samples using Fourier Transform Infrared (FTIR) analysis, and analysis of surface appearance via injection machine i.e., high pressure machine, and chemical test by methyl ethyl ketone (MEK), respectively.

\section{Acknowledgments}

This study was supported by Covestro, polyurethane (PUR) system house, Thailand (former Bayer materials science), providing chemicals and laboratory used. The authors would like to give a special thanks to PUR team for their kind intellectual and practical advises throughout the study.

\section{References}

1. Jiu-Jain WU and Run-Ping JIA, "Effect of Dimethyl Methylphoshonate (DMMP) flame retardant on Rigid polyurethane foam", (2017)

2. Rekha R. Rao, Lisa A. Mondy, Kevin N. Long, Mathew C. Celina, Nicholas Wyatt, et al., "The Kinetics of Polyurethane Structural Foam Formation: Foaming and Polymerization", AIChE Journal, Vol. 63, No. 7, July (2017)

3. Tesser R, Di Serio M, Sclafani A, Santacesaria E., "Modeling of polyurethane foam formation", . J Appl Polym Sci.;92:1875, (2004)

4. Dusek, K.; Spirkova, M. "Crosslinking and Network Formation in Polyurethane Systems with Excess Isocyanate"; Cell.Polym., 9/2, 69- 83, (1990)

5. Wang Huia, Wang Qing-songa, He Jia-jiaa, Mao Zhan-lia, Sun Jin-huaa, "Study on the Pyrolytic Behaviors and Kinetics of Rigid Polyurethane Foams", Procedia Engineering 52, 377 - 385, (2013)

6. Tomy Widya and Christopher W. Macosko,"Nanoclay-Modified Rigid Polyurethane Foam"Journal of Macromolecular Science, Part B: Physics, 44:897-908, (2005)

7. Kraehling H; Zipfel L, " Polyurethane Foams : Environmental Competitiveness of 365-MFC-Blown Products", Conference proceedings., Boston, Ma., 8th-11th, p.23-31Polyurethanes Conference, Oct. (2000)
8. Barthelemy P P; Leroy A Solvay Research \& Technology,"Progress in the Development of a new HFC Blowing Agent: a closer analysis of two leading candidates", Polyurethanes Expo '96. Conference Proceedings., Las Vegas, Nv., 20th-23rd, Oct. (1996)

9. W J Seo, H C Jung, W N Kim, "Mechanical, Morphological, and Thermal Properties of Rigid Polyurethane Foams Blown by Distilled Water [J]." J. Appl. Polym. Sci., 90 (1): 12-21, (2003)

10. M. Thirumal,1 Dipak Khastgir,1 Nikhil K. Singha,1 B. S. Manjunath,2 Y. P. Naik, "Effect of Foam Density on the Properties of Water Blown Rigid Polyurethane Foam", Journal of Applied Polymer Science, Vol. 108, 1810-1817, (2008)

11. Schilling S L., "Appliance rigid foams blown with cyclopentane and cyclopentane/ isopentane blends", J Cell Plast, 36(3): 190-205, (2000)

12. Li Xiaobin, CAO Hongbin \& ZHANG Yi. Structures and physical properties of rigid polyurethane foams with water as the sole blowing agent. J Science in China Series B: Chemistry, Vol.49 No.4 363-370, (2006)

13. H. C. Jung, S. C. Ryu, W. N. Kim, Y.-B. Lee, K. H. Choe, S.-B. Kim, "Properties of Rigid Polyurethane Foams Blown by HCFC 141B and Distilled Water", Journal of Applied Polymer Science, Vol. 81, 486493, (2001)

14. Li Xiaobin, CAO Hongbin, ZHANG Yi, Properties of Water Blown Rigid Polyurethane, Foams with Different Functionality, $J$ Wuhan University of Technology-Mater. Sci. Ed., 2008.

15. Woods, G. The ICI Polyurethane Handbook; Wiley: New York, (1990)

16. Oertel, G. Polyurethane Handbook; Hanser: New York, (1993)

17. Klempner, D.; Frisch, K. C. Handbook of Polymeric Foams and Foam Technology; Oxford University Press: New York, (1991)

18. T Kaiser., "Highly Crosslinked Polymers[J]", Prog. Polym. Sci.,14 (3): 373-450, (1989) 